\title{
Antibacterial and anti-adherence effects of a plant extract mixture (PEM) and its individual constituent extracts (Psidium sp., Mangifera sp., and Mentha sp.) on single- and dual- species biofilms
}

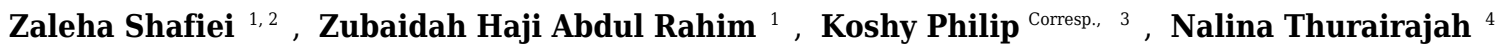 \\ 1 Department of Oral Biology and Biomedical Sciences, Faculty of Dentistry, University of Malaya, Kuala Lumpur, Malaysia \\ 2 Department of Clinical Oral Biology, Faculty of Dentistry, Universiti Kebangsaan Malaysia, Kuala Lumpur, Malaysia \\ 3 Institute of Biological Sciences, Faculty of Science,, University of Malaya, Kuala Lumpur, Malaysia \\ 4 Centre for Pre-U studies, UCSI University, Kuala Lumpur, Malaysia \\ Corresponding Author: Koshy Philip \\ Email address: kphil@um.edu.my
}

Background: Plant extracts mixture (PEM) and its individual constituent plant extracts (Psidium sp., Mangifera sp., Mentha sp.) are known to have an anti-adhering effect towards oral bacteria in the single-species biofilm. To date, the adhering ability of the early and late plaque colonisers (Streptococcus sanguinis and Streptococcus mutans) to PEM-treated experimental pellicle have not been investigated in dual-species biofilms. Methods: Fresh leaves of these plants were used in the preparation of the respective aqueous extract decoctions. The minimum inhibitory concentration (MIC) of the extracts towards $S$. sanguinis ATCC BAA-1455 and S. mutans ATCC 25175 was determined using a two-fold serial microdilution method. The sum of fractional inhibitory concentration ( $\Sigma F I C)$ index of PEM and its constituent plant extracts was calculated using the MIC values of the plants. The minimum bactericidal concentration (MBC) of the plant extracts was also determined. The anti-adherence effect of the plant extracts (individually and mixed) was carried out by developing simulated $S$. sanguinis and $S$. mutans respectively in single- and dual-species of biofilms in the Nordini's Artificial Mouth (NAM) model system in which the experimental pellicle was pretreated with the plant extract before bacterial inoculation. The bacterial population in the respective biofilms was quantified using ten-fold serial dilutions method and expressed as colony forming unit per $\mathrm{ml}(\mathrm{CFU} / \mathrm{ml})$. The bacterial population was also viewed using Scanning Electron Microscope (SEM). All experiments were done in triplicate. Results: The PEM compared with its respective constituent plants showed the lowest MIC towards $S$. sanguinis $(3.81 \mathrm{mg} / \mathrm{ml})$ and $S$. mutans $(1.91 \mathrm{mg} / \mathrm{ml})$ and exhibited a synergistic effect. The Psidium sp. (15.24 mg/ml) and, PEM and Psidium sp. (30.48 mg/ml) showed the lowest MBC towards $S$. sanguinis and $S$. mutans respectively. The anti-adherence effect of 
the PEM and its respective constituent plants (except Psidium sp.) was different for the two bacteria in the single-species biofilm. In the dual-species biofilms, PEM demonstrated similar anti-adherence effect towards $S$. sanguinis and S. mutans. The proportions of the bacterial population viewed under SEM appeared to be in agreement with the quantified population. Discussion: The combination of the active constituents of the individual plant extracts in PEM may contribute to its low MIC giving rise to the synergistic effect. The different anti-adherence effect towards $S$. sanguinis and S. mutans in both single- and dual-species biofilms could be due to the different proportion of the active constituents of the extracts and the interaction between different bacteria. The better adhering ability of $S$. sanguinis towards the PEM-treated pellicle when present together with $S$. mutans in the dual-species biofilms may suggest the potential of PEM in controlling the balance between the early and late colonisers in biofilms. 
1 Antibacterial and anti-adherence effects of a plant extract mixture (PEM) and its

2 individual constituent extracts (Psidium sp., Mangifera sp., and Mentha sp.) on single- and

3 dual-species biofilms.

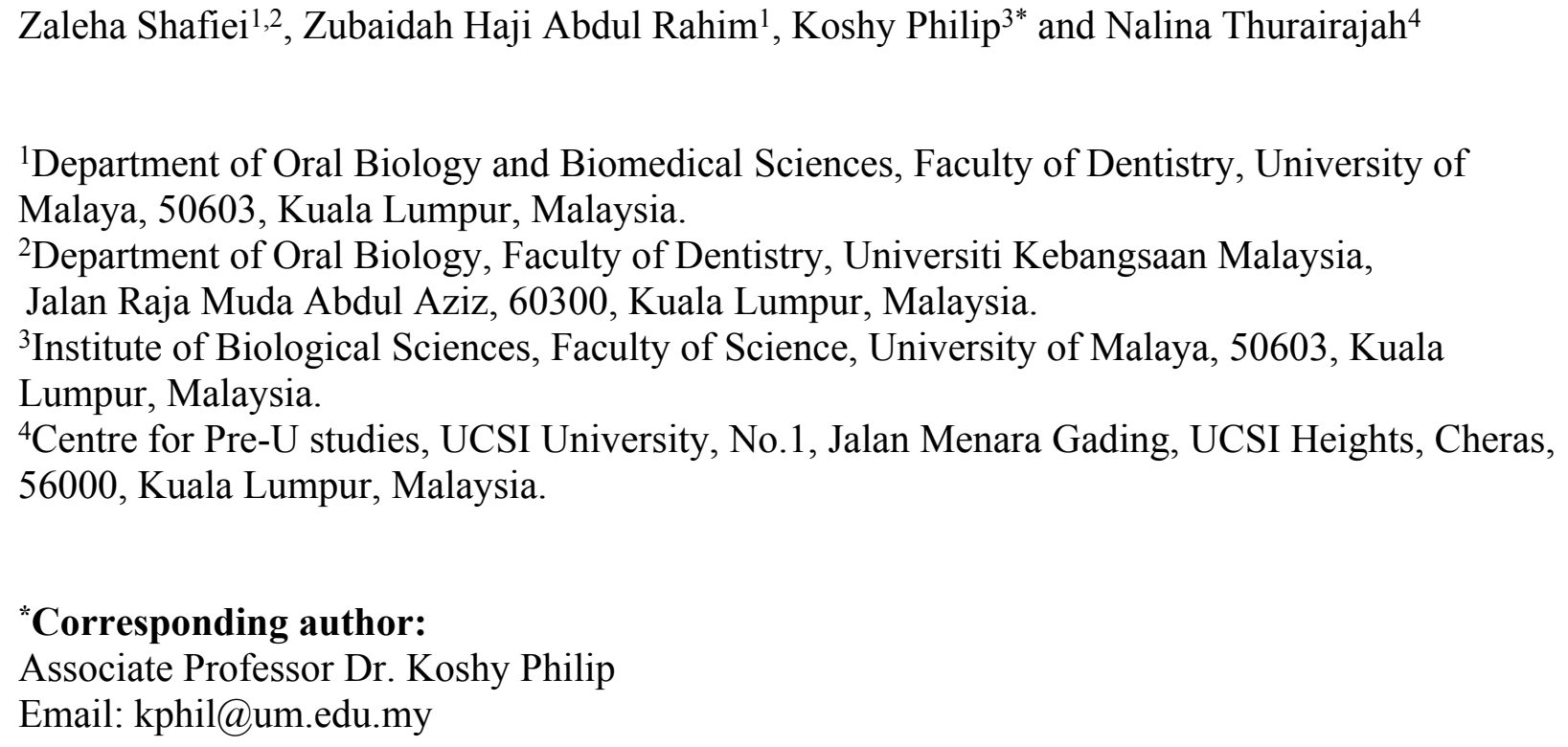




\section{ABSTRACT}

Background: Plant extracts mixture (PEM) and its individual constituent plant extracts (Psidium sp., Mangifera sp., Mentha sp.) are known to have an anti-adhering effect towards oral bacteria in the single-species biofilm. To date, the adhering ability of the early and late plaque colonisers (Streptococcus sanguinis and Streptococcus mutans) to PEM-treated experimental pellicle have not been investigated in dual-species biofilms.

Methods: Fresh leaves of these plants were used in the preparation of the respective aqueous extract decoctions. The minimum inhibitory concentration (MIC) of the extracts towards $S$. sanguinis ATCC BAA-1455 and S. mutans ATCC 25175 was determined using a two-fold serial microdilution method. The sum of fractional inhibitory concentration ( $\Sigma \mathrm{FIC}$ ) index of PEM and its constituent plant extracts was calculated using the MIC values of the plants. The minimum bactericidal concentration (MBC) of the plant extracts was also determined. The anti-adherence effect of the plant extracts (individually and mixed) was carried out by developing simulated $S$. sanguinis and $S$. mutans respectively in single- and dual-species of biofilms in the Nordini's Artificial Mouth (NAM) model system in which the experimental pellicle was pretreated with the plant extract before bacterial inoculation. The bacterial population in the respective biofilms was quantified using ten-fold serial dilutions method and expressed as colony forming unit per $\mathrm{ml}(\mathrm{CFU} / \mathrm{ml})$. The bacterial population was also viewed using Scanning Electron Microscope (SEM). All experiments were done in triplicate.

Results: The PEM compared with its respective constituent plants showed the lowest MIC towards $S$. sanguinis $(3.81 \mathrm{mg} / \mathrm{ml})$ and $S$. mutans $(1.91 \mathrm{mg} / \mathrm{ml})$ and exhibited a synergistic effect. The Psidium sp. (15.24 mg/ml) and, PEM and Psidium sp. $(30.48 \mathrm{mg} / \mathrm{ml})$ showed the lowest MBC towards $S$. sanguinis and $S$. mutans respectively. The anti-adherence effect of the PEM and its respective constituent plants (except Psidium sp.) was different for the two bacteria in the single-species biofilm. In the dual-species biofilms, PEM demonstrated similar anti-adherence effect towards $S$. sanguinis and $S$. mutans. The proportions of the bacterial population viewed under SEM appeared to be in agreement with the quantified population.

Discussion: The combination of the active constituents of the individual plant extracts in PEM may contribute to its low MIC giving rise to the synergistic effect. The different anti-adherence effect towards $S$. sanguinis and $S$. mutans in both single- and dual-species biofilms could be due to the different proportion of the active constituents of the extracts and the interaction between different bacteria. The better adhering ability of $S$. sanguinis towards the PEM-treated pellicle when present together with $S$. mutans in the dual-species biofilms may suggest the potential of PEM in controlling the balance between the early and late colonisers in biofilms. 


\section{INTRODUCTION}

88 Bacterial adherence has a central role in the pathogenesis of oral diseases such as dental caries

89

90

91

92

93

94

95

96

97

98

and periodontal diseases, which are also known as plaque-related diseases. The formation of dental plaque or oral biofilm is as follows. After tooth brushing, the tooth surface is immediately covered with saliva forming an acellular layer known as acquired pellicle. The acquired pellicle provides receptors for the oral bacteria to adhere and colonise. The pioneer bacteria that adhere to and subsequently colonise the acquired pellicle are known as early colonisers which include Streptococcus sanguinis (S. sanguinis), Streptococcus mitis (S. mitis) and Actinomyces sp. (Fathilah, Othman \& Rahim, 1999). It has been reported that Streptococcus mutans (S. mutans), the late settlers of the acquired pellicle are the causative agent of dental caries (Bowen, 2002). Bacteria in the oral cavity form a balanced population known as homeostasis and if imbalanced can lead to the initiation of oral diseases (Marsh \& Martin, 2009). Inhibition of bacterial adherence to the acquired pellicle may play a role in the prevention of oral diseases.

Fluoride and chlorhexidine are among the chemicals incorporated into oral healthcare products for the prevention of dental caries. They possess bactericidal activities and demonstrate many adverse effects such as vomiting, diarrhoea, taste disturbance and teeth staining (Chen \& Wang, 2010; Palombo, 2011).

Past studies have been reporting plants with a wide range of biological activities that could be useful for the development of alternative or adjunctive anti-plaque and anticaries therapies. Psidium guajava L. (Myrtaceae) (P. guajava) contains phenolic compounds that have multiple biological effects attributing to its antimicrobial and anticariogenic potentials (Prabu, Gnanamani \& Sadulla, 2006). Its leaves decoction have long been used in folklore practices to maintain oral hygiene by exhibiting positive anti-adherence towards the adhesion of the early 
110 colonisers onto saliva-coated glass surfaces (Fathilah \& Rahim, 2003). The extracts have the

111 ability to alter and disturb the surface characteristics of the early plaque settlers thus reducing

112 their adherence (Fathilah, Othman \& Rahim, 2006). Mangifera indica L. (Anacardiaceae)

113 (mango plant) (bark, roots and leaves) have been used in traditional medicine. Its leaves extract

114 can cause significant reduction of Prevotella intermedia and Porphyromonas gingivalis

115 compared to toothbrushing, a home care hygiene device (Bairy et al., 2002). Mentha piperita L.

116 (Lamiaceae) leaves extract contains tannin and flavonoids with antibacterial and antifungal

117 activities against selected oral pathogens. Its regular intake can ward off the initial colonisation 118 of pathogenic microbes (Pramila et al., 2012).

119 It has been shown in vitro that a mixture of aqueous extracts of three plant species (Psidium 120 sp., Mangifera sp. and Mentha sp.) which is referred as Plant Extract Mixture (PEM) in this 121 study has an anti-adherence effect towards early plaque colonisers (Nordini, Fathilah \& Rahim, 122 2013) and towards early and late colonisers (Rahim et al., 2014) in single-species biofilm. To 123 date, there is no study on the effect of PEM and its individual extracts on dual-species biofilms in 124 a dynamic environment. Thus, this study investigated the effects of PEM and its individual 125 constituent plant extracts towards the adherence of bacteria in single- and dual-species biofilms.

127 MATERIALS AND METHODS

128 Plant collection and extraction

129 Fresh leaves of Psidium sp. (voucher no. 48126) and Mangifera sp. (voucher no. 48124) were 130 obtained from Balai Ungku Aziz of the University of Malaya, Kuala Lumpur and the UPM 131 Agriculture Park, Selangor respectively. Leaves of Mentha sp. (voucher no. 48127) grown in 132 Cameron Highlands, Pahang, were obtained from a local market in Selangor, Malaysia. The 133 plants were identified at the Rimba Ilmu Herbarium (University of Malaya) and deposited under 
134 the stated voucher numbers. The fresh plant leaves were washed with tap water, followed by

135 deionised water, dried using tissue paper, weighed and cut into small pieces before boiling based

136 on the method described by Nalina \& Rahim (2006). Briefly, $1 \mathrm{~g}$ of fresh leaves was boiled in 1

137 L of deionised water for several hours until the final volume is one-third of the initial volume.

138 The decoction was then filtered using a muslin cloth to remove any debris and the clear filtrate

139 was further centrifuged at $1500 \times \mathrm{g}, 4^{\circ} \mathrm{C}$ for $15 \mathrm{~min}$ to eliminate any sediment. The supernatants

140 were filtered using Whatman No. 1 paper with a diameter of $150 \mathrm{~cm}$ and boiled again until the

141 final volume of $100 \mathrm{ml}$. The supernatants were then frozen overnight at $-80{ }^{\circ} \mathrm{C}$ followed by

142 freeze-drying for 2 days using freeze dryer (Eyela FDV-1200, China) in a sterile environment.

143 The sterile dried crude aqueous extracts were stored at $-20^{\circ} \mathrm{C}$ for further use.

\section{Preparation of bacterial suspension}

S. sanguinis ATCC BAA-1455 (strain SK36) and S. mutans ATCC 25175 used in this study

147 were obtained from American Type Culture Collection (ATCC, USA). Prior to the experiment, 148 the respective $20 \%$ glycerol stocks of each bacterium at $-80{ }^{\circ} \mathrm{C}$ were thawed at room temperature 149 and $1 \%$ of the strains were transferred in $20 \mathrm{ml}$ of sterile fresh Brain Heart Infusion (BHI) broth 150 (Oxoid Ltd, UK), incubated aerobically at $37{ }^{\circ} \mathrm{C}$ with shaking at $150 \mathrm{rpm}$ until mid-log phase of 151 growth (6-8 h). The bacterial suspensions were centrifuged at $5800 \mathrm{x} \mathrm{g}, 4{ }^{\circ} \mathrm{C}$ for $10 \mathrm{~min}$ and the 152 pellets were washed three times with ice-cold sterile deionised water, suspended in fresh BHI 153 broth and incubated at $37{ }^{\circ} \mathrm{C}$ for $15 \mathrm{~min}$ to reactivate their growth phase. The turbidity of each 154 strain was standardised by adjusting the absorbance to 0.144 (equivalent to $1.00 \times 10^{8} \mathrm{CFU} / \mathrm{ml}$ 155 and $1.53 \times 10^{7} \mathrm{CFU} / \mathrm{ml}$ for $S$. sanguinis and $S$. mutans respectively) at $550 \mathrm{~nm}$ using a 156 spectrophotometer (Shimadzu UV-1700, Japan). For dual-species, the standardised suspensions 
157 of the two bacteria were mixed $(1: 1 \mathrm{vol} / \mathrm{vol})$ prior to the experiment. The purity of the bacterial

158 cultures was checked each time prior to every experiment by streaking the culture broth on BHI 159 agar and incubated at $37^{\circ} \mathrm{C}$ for $24-48 \mathrm{~h}$.

160

161

Determination of minimum inhibitory concentrations (MIC), minimum bactericidal

162

163

164

165

166

167

168

169

170

171

172

173

174

175

176

177

178

179

concentrations $(\mathrm{MBC})$ and the sum of the fractional inhibitory concentration $(\Sigma F I C)$ index

A broth microdilution method in accordance with standard protocol CLSI (CLSI, 2012) and modified method of Kuete et al. (2009) were used to determine the MIC of PEM and its individual constituent plant extracts (Psidium sp., Mangifera sp. and Mentha sp.). About $1 \mathrm{~g}$ of sterile dried extract (Psidium sp.) was reconstituted in $7.81 \mathrm{ml}$ sterile deionised water giving a final concentration of extract at $128 \mathrm{mg} / \mathrm{ml}$. After sonication for $30 \mathrm{~s}$ and vortexing for $30 \mathrm{~min}$, the reconstituted extract was centrifuged at $1500 \times \mathrm{g}, 4{ }^{\circ} \mathrm{C}$ for $15 \mathrm{~min}$. The supernatant of the reconstituted extract was serially diluted two-fold in $\mathrm{BHI}$ broth to obtain a range of concentration $(0.25-64 \mathrm{mg} / \mathrm{ml})$ in respective test tubes labelled as $\mathrm{T} 1$ to $\mathrm{T} 9$. The diluted extracts were transferred into the corresponding wells of a 96-well microtitre plate (NUNC ${ }^{\mathrm{TM}}$ Brand products) as follows. To the first three rows of the 96-well microtitre plate labelled as A1 to A9; B1 to B9; C1 to C9 (carried out in triplicate to ensure reproducibility), $100 \mu 1$ of the respective serially diluted plant extract in BHI broth (T1 to T9) was added. To wells labelled as A11, B11, C11, 100 $\mu 1$ of BHI broth was added to ensure bacterial growth. To all of the wells above, $5 \mu 1$ of $S$. sanguinis suspension (standardised to $10^{6} \mathrm{CFU} / \mathrm{ml}$ ) was added. This gave the final concentration of the extract in the respective wells (A1 to A9; B1 to B9; $\mathrm{C} 1$ to $\mathrm{C} 9$ ) a range of concentration from 0.24-60.95 $\mathrm{mg} / \mathrm{ml}$. In addition to these, wells labelled as A12, B12, C12 was filled with $105 \mu \mathrm{l}$ of BHI broth just to ensure the sterility of the broth. To another row of wells, one row 
180 apart from the others (E1 to E9), $105 \mu 1$ of the two-fold serially diluted plant extract only was

181 added which served as blank control. The microtitre plate was sealed and covered with 182 aluminium foil, incubated aerobically at $37{ }^{\circ} \mathrm{C}$ with shaking at $150 \mathrm{rpm}$ for $24 \mathrm{~h}$. Following 183 incubation, the MIC was determined at $550 \mathrm{~nm}$ using ELISA reader based on turbidity 184 determined by comparing the absorbance of the suspension in wells of test extract (A1 to A9; B1 185 to B9; C1 to C9) with that of the corresponding blank control. The MIC of each compound was 186 defined as the lowest concentration that inhibited the bacterial growth. Similar procedure was 187 repeated with $S$. mutans. The similar experiment was repeated for the other plant extracts 188 (Mangifera sp., Mentha sp. and PEM). For PEM, an equal volume of the stock solution of extracts (Psidium sp., Mangifera sp. and Mentha sp.) each with a concentration of $128 \mathrm{mg} / \mathrm{ml}$ was mixed followed by two-fold serial dilution.

For the MBC determination, $20 \mu \mathrm{l}$ of the bacterial suspension from selected wells (A1 to A9; B1 to B9; C1 to C9) which showed almost no turbidity was inoculated on BHI agar (Oxoid Ltd, UK) and incubated for $48 \mathrm{~h}$ at $37^{\circ} \mathrm{C}$. The lowest concentration of the extracts that showed no growth corresponded to the MBC value.

The sum of the fractional inhibitory concentration ( $\Sigma$ FIC) determines the synergy of the plant extracts, calculated using the following equation:

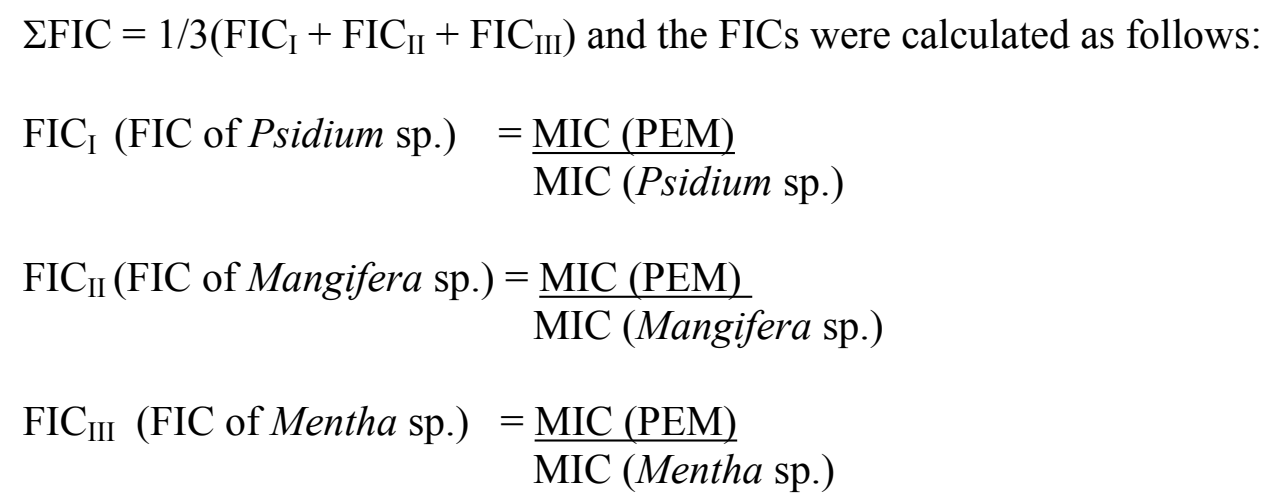


207 The $\Sigma$ FIC index determines the interaction between the different plant extracts in the mixture

208 where the interaction is interpreted according to a range of values; value less than 0.5 as

209 synergistic, value greater than 0.5 to 1 as additive, value greater than 1 to 4 as indifferent and 210 value greater than 4 as antagonistic (Van Vuuren and Viljoen, 2011).

211

212 Preparation of Sterilised Saliva

213 Undiluted sterile saliva was prepared according to the method described by De Jong \& Van der 214 Hoeven (1987) and Nordini et al. (2013). To minimize variation, a single volunteer was used to 215 collect $100 \mathrm{ml}$ of stimulated whole saliva (SWS). The SWS collection was done by expectoration 216 after chewing sugar-free gum (before eating or at least $2 \mathrm{~h}$ after eating) in ice-chilled test tubes.

217 The aggregation of the protein in the SWS was minimised by adding 1,4-Dithio-DL-threitol 218 (DTT) (GE Healthcare, Sweden) to a final concentration of $2.5 \mathrm{mM}$. The mixture was stirred 219 slowly for $10 \mathrm{~min}$ followed by centrifugation at $800 \mathrm{x} \mathrm{g}, 4{ }^{\circ} \mathrm{C}$ for $30 \mathrm{~min}$. The supernatant was 220 then filter sterilised through a disposable $0.22 \mu \mathrm{m}$ low-protein-binding filter (Cellulose acetate 221 syringe filters Sartorius, USA) into sterile centrifuge tubes and stored at $-20^{\circ} \mathrm{C}$ until further use. 222 Prior to the experiment, the sterile SWS was thawed and centrifuged to remove any precipitate. It 223 was later used to coat glass beads (3 mm in diameter) (Merck, Germany) in an artificial mouth 224 (NAM) model forming a layer that mimics the acquired pellicle on the tooth surface and thus 225 referred as the Experimental Pellicle.

\section{Ethical approval}

228 The study protocol was reviewed and approved by the Ethics committee of Faculty of Dentistry 229 University of Malaya, Kuala Lumpur, Malaysia (The Ethic committee/IRB reference number: 
230 DF OB1506/0070(P). Written informed consent was obtained from one donor for saliva

231 collection.

232

233 Anti-adherence effect of plant extracts

234 Prior to use, the dried aqueous extracts were reconstituted in sterile deionised water to a final

235 concentration of $0.5 \mathrm{mg} / \mathrm{ml}$. The reconstituted extracts were further sterilised by filtration using

$2360.22 \mu \mathrm{m}$ nylon syringe filters (Millipore Billerica, USA). For PEM, the same concentrations of

237 the sterile reconstituted individual extracts were mixed $(1: 1: 1 \mathrm{vol} / \mathrm{vol} / \mathrm{vol})$ to give a mixture of 238 extracts of the same concentration $(0.5 \mathrm{mg} / \mathrm{ml})$.

239 Nordini's Artificial Mouth (NAM) model developed by Rahim et al. (2008) was used in the

240 in vitro study of the anti-adherence effect of PEM and its individual constituent plant extracts

241 towards the early and late plaque colonisers in single- and dual-species biofilms. The NAM

242 model was used in the study to represent oral cavity. The model consists of a glass chamber $(1 \mathrm{x}$

$2436 \mathrm{~cm}$ length), glass beads (3 $\mathrm{mm}$ diameter), water bath system, saliva reservoir, bacterial

244 reservoir and a peristaltic pump. In this study, nine glass beads were placed in the glass chamber

245 of the NAM model. The glass beads represent the tooth surface. The glass chamber which was

246 immersed in the water bath system, set at $37^{\circ} \mathrm{C}$ represents the oral cavity. The peristaltic pump

247 (Masterflex L/S, USA) of the NAM model was used to flow the saliva/test extract/bacteria from

248 the reservoir into the system via rubber tubing at a constant flow rate $(0.3 \mathrm{ml} / \mathrm{min}$ for resting

249 saliva). The experiment was carried out as follows. Saliva was first flowed into the NAM model

250 for $2 \mathrm{~min}$ at a constant rate to form an experimental pellicle on the glass beads. Excess saliva was

251 rinsed off by allowing sterile deionised water to flow in for $2 \mathrm{~min}$. This allowed the experimental

252 pellicle to be pretreated with sterile deionised water. Following this, S. sanguinis which was 
253 standardised to 0.144 absorbance at $550 \mathrm{~nm}$ wavelength was allowed to flow into the NAM

254 model for $24 \mathrm{~h}$ to form a 24-h biofilm on the experimental pellicle-coated glass beads.

255 Of the nine glass beads, three were taken out randomly whereas the remaining six glass

256 beads were kept for SEM viewing and reserves. The three glass beads were then individually

257 placed in a sterile microcentrifuge tube containing $1 \mathrm{ml}$ Phosphate Buffered Saline (PBS) (pH

258 7.4), sonicated for 10 seconds and vortexed for one minute to dislodge the attached bacteria. The

259 suspension was serially diluted ten-fold $\left(10^{-1}\right.$ to $10^{-5}$ dilutions $)$ with PBS. A $100 \mu$ of the

260 homogeneous bacterial suspension from each tube was pipetted out and plated on three separate

261 BHI agar plates using the Lawn method. The plates were incubated for $24 \mathrm{~h}$ at $37{ }^{\circ} \mathrm{C}$. The

262 counting of all viable microorganisms formed on the plate done using colony counter. Plates

263 from the dilution which gave a CFU number of between 30-300 colonies were selected and used

264 in the calculation of the growth population. The bacterial suspension used in the plating was 100

$265 \mu \mathrm{l}$ and hence it was expressed as $\mathrm{CFU} / \mathrm{ml}$ based on the following formula:

266

267

Total CFU $/ \mathrm{ml}=$ Number of colonies

268

Volume plated (ml) x Dilution factor

269 The deionized water treated experimental pellicle served as negative control for S. sanguinis in

270 single-species biofilm and the bacterial population (total $\mathrm{CFU} / \mathrm{ml}$ ) assumed as $100 \%$ bacterial

271 adherence. Similar procedure was repeated with $S$. mutans (standardised to 0.144 absorbance at

$272550 \mathrm{~nm}$ ) for single-species biofilm. For dual-species biofilms, the individual strain was mixed in

273 equal amount $(1: 1 \mathrm{vol} / \mathrm{vol})$ and a similar procedure was repeated. In the dual-species biofilms,

274 the two bacteria were differentiated according to their colony sizes. S. mutans colony is larger

275 than S. sanguinis allowing the colonies to be counted separately. 

with respective plant extract (Psidium sp./ Mangifera sp./ Mentha sp./PEM) at sub-MIC (0.5

278

$\mathrm{mg} / \mathrm{ml}$ ) before inoculation with bacterial suspension used for the development of single- and dual-species biofilms. For positive control, the experimental pellicle was pretreated with $0.12 \%$ chlorhexidine gluconate (CHX). The individual experiment was carried out in triplicate.

Percentage of adherence $(\mathrm{X})$ was calculated using the equation below:

$$
\mathrm{X}=\frac{\text { adhered cells (test or positive control) }}{\text { adhered cells (negative control) }} \times 100
$$

Assuming the bacterial adherence to negative control was $100 \%$, the percentage of antiadherence was calculated as:

$$
\% \text { Anti-adherence }=100-\mathrm{X}
$$

\section{Scanning Electron Microscopy (SEM) analysis of cell population on glass beads}

The remaining beads from the experiments were processed for SEM viewing according to the method described by Rahim \& Thurairajah (2011) with slight modification. Briefly, three glass beads for each of experiment were fixed with $1 \mathrm{ml}$ of $4 \%$ glutaraldehyde solution (prepared in sodium cacodylate buffer, $\mathrm{pH} 7.4$ ) and kept at $4{ }^{\circ} \mathrm{C}$ until the subsequent analysis. Prior the analysis, 4\% glutaraldehyde solution was pipetted out and washed twice with sodium cacodylate buffer for $15 \mathrm{~min}$, followed by postfixing with $2 \%$ (vol/vol) osmium tetroxide in 1\% (wt/vol) sodium cacodylate buffer solution for 1 hour and kept at $4{ }^{\circ} \mathrm{C}$. Then, the glass beads were rinsed with deionised water twice for 15 min before dehydration process. A series of 30, 50, 70, 80, and $95 \%$ ethanol at an interval of 15 min was used for dehydration process. This was followed by dehydration carried out twice for 15 min each using $100 \%$ ethanol. Ethanol was gradually displaced with acetone in the following ratios (vol/vol); Ethanol:Acetone 3:1, 1:1, 1:3 each for 
$30120 \mathrm{~min}$ and finally followed by $100 \%$ acetone three times for $20 \mathrm{~min}$. The dehydrated samples

302 were then subjected to Critical Point Drying (CPD) (Balzers CPD 030, Liechtenstein) for 1 h 40

$303 \mathrm{~min}$ in liquid $\mathrm{CO}_{2}$ under 95 bar pressure. The glass beads were then kept in a tight container in a

304 desiccator. Prior to SEM viewing, the beads were gold-coated under low pressure with ion

305 sputter coater (Joel JFC1100, Japan). The beads were viewed for cell population at 10,000X

306 magnification using Scanning Electron Microscope (Quante FEG 250, Holland).

307

308

\section{Statistical analysis}

309 The experiments were repeated and analysed using three triplicates and expressed as a mean \pm

310 standard deviation, where the number of determinations, $n=27$. Data were analysed using IBM

311 SPSS statistical software, version 23. The Shapiro-Wilk test was used to test assumptions of

312 normality. The results were analysed using Kruskal-Wallis and Mann-Whitney tests for non-

313 parametric statistical analysis to compare the difference between the two independent groups.

314 Results were considered significant at $p<0.05$.

\section{RESULTS}

317

Minimum inhibitory concentrations (MIC), minimum bactericidal concentrations (MBC) and the sum of the fractional inhibitory concentration ( $\Sigma$ FIC) index of plant extracts

Table 1 shows the MIC, MBC and SFIC index of the PEM and its individual constituent plant extracts against the early (S. sanguinis) and late ( $S$. mutans) plaque colonisers. The MIC values of PEM (S. sanguinis $3.81 \mathrm{mg} / \mathrm{ml}$; S. mutans $1.91 \mathrm{mg} / \mathrm{ml}$ ) were lower than those of the individual extracts for the two bacteria. Among its individual constituent plant extracts, the Psidium sp.

323 showed the lowest MIC against $S$. mutans $(3.81 \mathrm{mg} / \mathrm{ml})$ whereas Mentha sp. and Psidium sp. 
324 have almost similar MIC against $S$. sanguinis $(7.62 \mathrm{mg} / \mathrm{ml})$. It is shown that the MBC were 325 higher than the MIC for all the extracts. Psidium sp. (MBC value of $15.24 \mathrm{mg} / \mathrm{ml}$ ) showed the

326 higher bactericidal effect compared with Mangifera sp., Mentha sp. and PEM (MBC value of $32730.48 \mathrm{mg} / \mathrm{ml}$ ) against $S$. sanguinis. The MBC value exhibited by PEM and Psidium sp. against $S$. 328 mutans $(30.48 \mathrm{mg} / \mathrm{ml})$ was lower compared with Mangifera $\mathrm{sp}$. and Mentha $\mathrm{sp} .(60.95 \mathrm{mg} / \mathrm{ml})$. It 329 was found from the calculation of the $\Sigma F I C$ index, the interactions of the plant extracts are 330 synergistic for the two bacteria where the index is lower for $S$. mutans $(\Sigma \mathrm{FIC}=0.25)$ compared 331 with $S$. sanguinis $(\Sigma \mathrm{FIC}=0.42)$.

\section{Bacterial population adhering to the experimental pellicle}

The bacterial population for $S$. sanguinis and $S$. mutans adhering to experimental pellicle without treatment (negative control) either individually (single-species) or together (dual-species) is shown in Table 2. In a single-species biofilm, the population of $S$. mutans $\left((2.48 \pm 0.16) \times 10^{7}\right.$ $\mathrm{CFU} / \mathrm{ml}$ ) adhering to the experimental pellicle was ten times higher compared with $S$. sanguinis $\left((2.30 \pm 0.37) \times 10^{6} \mathrm{CFU} / \mathrm{ml}\right)$ and it is statistically significant $(\mathrm{p}<0.05)$. However, in dualspecies biofilms, the $S$. mutans population $\left((1.54 \pm 0.35) \times 10^{7} \mathrm{CFU} / \mathrm{ml}\right)$ adhered in similar proportions with $S$. sanguinis $\left((1.49 \pm 0.36) \times 10^{7} \mathrm{CFU} / \mathrm{ml}\right)$.

\section{Anti-adherence effect of plant extracts in single- and dual-species biofilms}

Figure 1 shows the anti-adherence effects of PEM and its respective constituent plant extracts in single-species biofilm ( $S$. sanguinis and $S$. mutans). The anti-adhering effect of all the extracts mutans. 
Figure 2 shows the anti-adherence activities of the PEM and its individual constituent plant extracts in the dual-species biofilms. It was observed that Psidium sp. also demonstrated similar and higher anti-adherence activities towards $S$. sanguinis $(88.54 \pm 4.47 \%)$ and $S$. mutans $(88.65$ $350 \pm 3.22 \%$ ) compared with PEM, Mangifera sp. and Mentha sp. The Mentha sp. exhibited 351 significantly higher anti-adherence activity towards $S$. sanguinis $(70.12 \pm 6.90 \%)$ compared with 352 S. mutans $(50.54 \pm 18.64 \%)$. PEM demonstrated comparable anti-adherence effect towards $S$. sanguinis and $S$. mutans $(47.50 \pm 17.93 \%$ and $49.08 \pm 18.90 \%$ respectively).

\section{Bacterial adherence to plant extracts treated-experimental pellicle viewed under SEM}

Figures 3 and 4 show the SEM photographs of single-species biofilm viewed at 10,000X magnification displaying the cell population adhering to the experimental pellicle (saliva-coated glass beads) treated with plant extracts as well those of the negative and positive controls. The population of $S$. mutans and $S$. sanguinis were almost zero in single-species biofilm adhering to extract-treated when compared with the negative control.

Figure 5 shows the SEM photographs of the dual-species biofilms. It was observed that the population of the two bacteria adhering to Psidium sp.-treated experimental pellicle was highly reduced (Fig. 5D). It was different for Mentha sp-treated experimental pellicle, the adhered population of S. sanguinis was less compared with S. mutans (Fig. 5F). The adherence of the two bacteria to Mangifera sp.- (Fig. 5E) and PEM-treated experimental pellicle (Fig. 5C) respectively were almost comparable.

\section{DISCUSSION}


370 In this study, the MIC value of Psidium sp. against S. sanguinis was higher $(7.62 \mathrm{mg} / \mathrm{ml})$

371 compared with what has been reported by Fathilah (2011) which is $4.69 \mathrm{mg} / \mathrm{ml}$. The difference

372 could be due to the bacterial strain used in which used clinical isolate whereas in this study the

373 bacterial strain was purchased from ATCC. Prabu et al. (2006) have reported the MIC value of 374 guaijaverin $(4 \mathrm{mg} / \mathrm{ml})$ towards $S$. mutans MTCC 1943. Guaijaverin is a biologically active 375 flavonoid of P. guajava (Prabu et al., 2006). The value obtained from our study can be 376 considered within range as we were using the crude aqueous extract.

377 PEM which is a mixture of equal amount of Psidium sp., Mangifera sp. and Mentha sp. has

378 low MIC compared with its individual constituent plant extracts. This suggests that PEM is a

379 better growth inhibitor which may be attributed to the combination of the active constituents of 380 the individual plant extracts, a synergistic interaction as indicated by the $\Sigma$ FIC index.

PEM has the same MBC value towards S. sanguinis and S. mutans indicating that it exerts

382 similar bactericidal effect against the two bacteria. However, the Psidium sp. has lower MBC 383 value compared with PEM towards $S$. sanguinis. The lower MBC value might be due to $S$. 384 sanguinis aggregating in the presence of Psidium sp. (Fathilah, 2011) as the aggregated $S$. 385 sanguinis may not be reflected during plating. The similar MBC value of PEM towards the two 386 bacteria indicate that PEM has component(s) that may be bactericidal to both. The synergistic 387 effects of the individual constituent plant extracts in PEM contribute to its bactericidal and 388 growth inhibitory effects. It has been reported that there are synergistic interactions for 389 constituents within a total extract of a single herb, as well as between different herbs in a 390 formulation (Williamson, 2001; Nahrstedt \& Butterweck, 2010).

391 Bacterial adherence has a central role in the formation of dental plaque (Jakubovics \& 392 Kolenbrander, 2010). It is initiated by the formation of acquired pellicle on the tooth surface 
393 which then become the substratum for bacteria colonization (Jakubovics \& Kolenbrander, 2010).

394 Dental plaque, if not controlled, will subsequently lead to dental caries and periodontitis. It has

395 been a normal practice to brush teeth after meals. The scenario may be different if oral healthcare

396 products are to be used before meals. In this study, we simulate the use of healthcare product

397 before meals by treating the experimental pellicle with plant extracts before inoculating it with

398 the bacteria. This determines the adhering ability of bacteria towards the treated experimental

399 pellicle. Using the plant extract at sub-MIC range (Hasan, Danishuddin \& Khan, 2015) will

400 allow adherence by viable cells only. The final concentration of PEM and its individual

401 constituent plant extracts $(0.5 \mathrm{mg} / \mathrm{ml})$ that were used in this study was well below the MIC which

402 has also been used for PEM in previous studies in single-species biofilm (Rahim et al., 2014).

403 In this study, the trend of adhered bacterial population to the experimental pellicle is 404 different in single-species compared with dual-species biofilms. In single-species, the adhered $S$.

405 sanguinis population was 10 -fold lower compared with that of $S$. mutans. This is agreement with

406 what has been reported by Rahim et al. (2014). This may suggest that in single-species biofilm,

407 the bacterium ( $S$. sanguinis and $S$. mutans respectively) interacts independently with the

408 components of the experimental pellicle. The behaviour of the bacterial population was found to

409 be different when they exist together in dual-species biofilms in which the two bacteria were

410 inoculated at the same time. The adhered bacterial population of the two bacteria was almost in

411 equal proportion. This can be attributed to the reduced competition between the bacteria when

412 they are inoculated at the same time as has been reported by Kreth et al. (2005).

413 The normal adhering process of the early and late colonisers (S. sanguinis and S. mutans

414 respectively) is disturbed when the experimental pellicle is pretreated with plant extracts before

415 inoculation (Rahim et al., 2014). Their study involved single-species biofilm while our study 
416 included single- and dual-species biofilms in a dynamic environment. In a single-species biofilm, 417 the PEM showed a higher anti-adhering activity towards $S$. sanguinis compared with $S$. mutans.

418 The individual constituent plant extracts except Psidium sp. also showed the same profile of anti419 adherence. The latter is not in agreement with what has been reported by Rahim et al. (2014) which 420 was carried out in the same dynamic environment. The discrepancy could be due to the different 421 strain of $S$. sanguinis used in our study. In the dual-species biofilms, the pretreatment of experimental 422 pellicle with the plant extracts demonstrated a different profile of anti-adhering activity compared to single423 species. The anti-adhering activity exhibited by the Psidium sp. towards the two bacteria is highest 424 compared with the other extracts. PEM showed almost similar or about $50 \%$ of the anti-adhering activity compared with the negative controls towards the two bacteria. This suggests that the adherence of $S$. 426 mutans to PEM-treated experimental pellicle enhanced the adherence of $S$. sanguinis when they 427 are together. The balanced bacterial population is important to maintain oral health against the 428 emergence of pathogenic bacteria following an imbalance in the oral resident microbiota (Marsh $429 \&$ Martin, 2009). For example, the excess population of $S$. mutans can lead to the initiation of dental caries (Bowen, 2002). The increase in the adherence of $S$. sanguinis in the presence of $S$. mutans as in the dual-species may be attributed to modification of the complementary binding sites between the adhesins on the bacterial surface and receptors on the treated pellicle (Rahim et 433 al., 2014). The population of S. sanguinis, a normal oral microflora, should be maintained as it 434 has the ability to generate antibacterial substance towards putative periodontal pathogens ( $M a$ et 435 al., 2014) where the loss of its colonization appears to be associated with aggressive periodontitis 436 (Stingu et al., 2008). The colonization of S. sanguinis provides suitable substratum for 437 colonization of $S$. mutans following which the population of $S$. sanguinis is reduced (Caufield et 
438 al., 2000; Kreth et al., 2005). The positive control, 0.12\% CHX appeared to have no adhering

439 activity as the concentration used is more to the bactericidal (Rahim \& Thurairajah, 2011).

440 The anti-adhering activity observed in plant extracts treated-experimental pellicle is a reflection of

441 viable cell adherence since the concentration used in the study was in the sub-MIC range. The phenolic

442 content of the plant extracts (Thimothe et al., 2007) may interfere the adherence of the bacterial

443 cells to the experimental pellicle. The reduced adherence may subsequently affect the biofilm

444 formation (Rahim et al., 2014; Barnabé et al., 2014).

445 The bacterial colonies adhering to the experimental pellicle (or plant extract-treated and 446 untreated) corresponded with the bacterial population viewed under SEM confirming the effect 447 of plant extracts. The Psidium sp. appears to aggregate S. sanguinis (Fig. 3D) and this is in 448 agreement with what had been reported by Fathilah (2011). Future studies may include the 449 inoculation of early coloniser prior to the late coloniser for dual-species biofilms. This is to study 450 whether the early coloniser to the plant extracts treated experimental pellicle has any influence 451 on the adherence of the later coloniser.

452

453

CONCLUSION

PEM appears to demonstrate a balanced population of the early- $(S$. sanguinis $)$ and late- $(S$. mutans) plaque colonisers. This may suggest its potential use as an oral healthcare product in 456 controlling the development of periodontitis and caries.

457

458

\section{ACKNOWLEDGEMENTS}

459 I would like to acknowledge all the lab staff at Balai Ungku Aziz Research Lab for providing the 460 place and equipment to do the study. SEM was performed at Electron Microscopy Lab, Faculty 
461 of Medicine, UM and Faculty of Dentistry, UM for processing and viewing SEM samples

462 respectively.

463

464

465

466

467

468

469

470

471

472

473

474

475

476

477

478

479

480

481

482

483

484

485

486

487

488

489

490

491

492

493

494

495

496

497

498

499

500

501

502

\section{REFERENCES}

Bairy I, Reeja S, Siddharth RPS, Bhat M, Shivananda PG. 2002. Evaluation of antibacterial activity of Mangifera indica on anaerobic dental microflora based on in vivo studies. Indian Journal of Pathology and Microbiology 45:307-310.

Barnabé M, Saraceni CHC, Dutra-Correa M, Suffredini IB. 2014. The influence of Brazilian plant extracts on Streptococcus mutans biofilm. Journal of Applied Oral Sciences 22(5):366-372. http://dx.doi.org/10.1590/1678-775720140085.

Bowen WH. 2002. Do we need to be concerned about dental caries in the coming millennium? Critical Review of Oral Biology and Medicine 13(2):126-131. DOI $10.1177 / 154411130201300203$.

Caufield PW, Dasanayake AP, Li Y, Pan Y, Hsu J, Hardin JM. 2000. Natural history of Streptococcus sanguinis in the oral cavity of infants: evidence for a discrete window of infectivity. Infection and Immunity 68:4018-4023.

Chen F, Wang D. 2010. Novel technologies for the prevention and treatment of dental caries: a patent survey. Expert Opinion on Therapeutic Patents 20(5):681-694. DOI $10.1517 / 13543771003720491$.

CLSI. 2012. Methods for dilution antimicrobial susceptibility tests for bacteria that grow aerobically; approved standard-9th ed. CLSI document M07-A9 Wayne: Clinical and Laboratory Standards Institute.

De Jong, M. Van der Hoeven, J. 1987. The growth of oral bacteria on saliva. Journal of Dental Research 66(2):498-505.

Fathilah AR, Othman RY, Rahim ZHA. 1999. An in vitro study on the anti- adherence properties of a mouth rinse containing chlorhexidine gluconate and hexetidine. Annal Dental of University of Malaya 6:17-20.

Fathilah AR, Othman RY, Rahim ZHA. 2006. The effect of Piper betle and Psidium guajava extracts on the cell surface hydrophobicity of selected early settlers of dental plaque. Journal of Oral Sciences 48(2):71-75.

Fathilah AR, Rahim ZHA, Othman RY, Yusoff M. 2009. Bacteriostatic effect of Piper betle and Psidium guajava extracts on dental plaque bacteria. Pakistan Journal of Biological Sciences 12(6):518-521. 
503

504

505

506

507

508

509

510

511

512

513

514

515

516

517

518

519

520

521

522

523

524

525

526

527

528

529

530

531

532

533

534

535

536

537

538

539

540

541

542

543

544

Fathilah AR, Rahim ZHA. 2003. The anti-adherence effect of Piper betle and Psidium guajava extract on the addition of early settlers in dental plaque to saliva-coated glass surfaces. Journal of Oral Sciences 45(4):201-206.

Fathilah, AR. 2011. Piper betle L. and Psidium guajava L. in oral health maintenance. Journal of Medicinal Plants Research 5(2):156-163.

Hasan S, Danishuddin M, Khan AU. 2015. Inhibitory effect of Zingiber officinale towards Streptococcus mutans virulence and caries development: in vitro and in vivo studies. BMC Microbiology 15(1):1-14. DOI 10.1186/s12866-014-0320-5.

Jakubovics NS, Kolenbrander PE. 2010. The road to ruin: the formation of disease-associated oral biofilms. Oral Disease 16:729-739. DOI 10.1111/j.1601-0825.2010.01701.x.

Kreth J, Merritt J, Shi W, Qi F. 2005. Competition and coexistence between Streptococcus mutans and Streptococcus sanguinis in the dental biofilm. Journal of Bacteriology 185:7193-7203. DOI 10.1128/JB.187.21.7193-7203.2005.

Kuete V, Fozing DC, Kapche WFGD, Mbaveng AT, Kuiate JR, Ngadjui BT, et al. 2009. Antimicrobial activity of the methanolic extract and compounds from Morus mesozygia stem bark. Journal of Ethnopharmacology 124:551-555. DOI 10.1016/j.jep.2009.05.004.

Ma S, Li H, Yan C, Wang D, Li H, Xia X, et al. 2014. Antagonistic effect of protein extracts from Streptococcus sanguinis on pathogenic bacteria and fungi of the oral cavity. Experimental and Therapeutic Medicine 7(6):1486-1494. DOI 10.3892/etm.2014.1618.

Marsh P, Martin M. 2009. Oral Microbiology. UK: Churchill Livingstone Elsevier.

Nahrstedt A, Butterweck V. 2010. Lessons learned from herbal medicinal products: the example of St. John's wort. Journal of Natural Products 73:1015-1021. DOI: 10.1021/np1000329.

Nalina T, Rahim ZHA. 2006. Effect of Piper betle L. leaf extract on the virulence activity of Streptococcus mutans- An in vitro study. Pakistan Journal of Biological Sciences 9(8):1470-1476.

Nordini WHWI, Fathilah AR, Rahim ZHA. 2013. Plant extracts of Psidium guajava, Mangifera sp. and Mentha sp. inhibit the growth of the population of single-species oral biofilm. Alterative \& Integrative Medicine 2:102-106.

Palombo E.A. 2011. Traditional medicinal plant extracts and natural products with activity against oral bacteria: potential application in the prevention and treatment of oral diseases. Evidence-Based Complementary and Alternative Medicine Article ID 680354:1-15. http://dx.doi.org/10.1093/ecam/nep067.

Prabu GR, Gnanamani A, Sadulla S. 2006. Guaijaverin - a plant flavonoid as a potential antiplaque agent against Streptococcus mutans. Journal of Applied Microbiology 101:487495. DOI 10.1111/j.1365-2672.2006.02912.x. 
545

562

563

564

565

566

567

568

569

570

571

572

573

574

575

576

577

578

579

580

581

582
Pramila DM, Xavier R, Marimuthu K, Kathiresan S, Khoo MLML, Senthilkumar M, et al. 2012. Phytochemical analysis and antimicrobial potential of methanolic leaf extract of peppermint (Mentha piperita: Lamiaceae). Journal of Medicinal Plants Research 6(2):331335. DOI 10.5897/JMPR11.

Rahim ZHA, Fathilah AR, Irwan S, Nordini WHWI. 2008. An artificial mouth system (NAM model) for oral biofilm research. Research Journal of Microbiology 3(6):466-473. DOI 10.3923/jm.2008.466.473.

Rahim ZHA, Shaikh S, Nordini WHWI, Harun WHW, Fathilah AR. 2014. The effect of selected plant extracts on the development of single-species dental biofilms. Journal of the College of Physicians and Surgeons Pakistan 4(11):796-801.

Rahim ZHA, Thurairajah N. 2011. Scanning electron microscopic study of Piper betle L. leaves extract effect against Streptococcus mutans ATCC 25175. Journal of Applied Oral Sciences 19(2):137-146. DOI 10.1590/S1678-77572011000200010.

Stingu CS, Eschrich K, Rodloff AC, Schaumann R, Jentsch H. 2008. Periodontitis is associated with a loss of colonization by Streptococcus sanguinis. Journal of Medical Microbiology 57(4):495-499. DOI 10.1099/jmm.0.47649-0.

Thimothe, J, Bonsi, IA, Padilla-Zakour, OI, Koo, H. 2007. Chemical characterization of red wine grape (Vitis vinifera and Vitis interspecific hybrids) and pomace phenolic extracts and their biological activity against Streptococcus mutans. Journal of Agriculture and Food Chemistry 55:10200-10207.

Van Vuuren S, Viljoen A. 2011. Plant-based antimicrobial studies - methods and approaches to study the interaction between natural products. Planta Medica 77:1168-82. DOI 10.1055/s0030-1250736.

Williamson EM. 2001. Synergy and other interactions in phytomedicines. Phytomedicine 8:401409. 
583 584

Table 1. The MIC, MBC and FIC value of PEM and its individual constituent plant extracts against tested oral bacteria.

\begin{tabular}{|c|c|c|c|c|c|c|c|c|c|}
\hline & \multicolumn{4}{|c|}{${ }^{\mathrm{a}} \mathrm{MIC}(\mathrm{MBC})(\mathrm{mg} / \mathrm{ml})$} & \multicolumn{5}{|c|}{ Fractional inhibitory concentration index } \\
\hline & $\begin{array}{l}\text { Psidium } \\
\text { sp. }\end{array}$ & $\begin{array}{c}\text { Mangife } \\
\text { ra } \mathrm{sp} .\end{array}$ & $\begin{array}{c}\text { Menth } \\
a \mathrm{sp} .\end{array}$ & bPEM & $\mathrm{FIC}_{\mathrm{I}}$ & $\mathrm{FIC}_{\mathrm{II}}$ & $\mathrm{FIC}_{\mathrm{III}}$ & $\begin{array}{c}{ }^{\mathrm{c}} \Sigma \mathrm{FIC}=1 / 3 \\
\left(\mathrm{FIC}_{\mathrm{I}}+\mathrm{FIC}_{\mathrm{II}}\right. \\
\left.+\mathrm{FIC}_{\mathrm{III}}\right)\end{array}$ & $\begin{array}{c}\text { Inter } \\
\text { actio } \\
\mathrm{n}\end{array}$ \\
\hline $\begin{array}{l}S . \\
\text { sanguinis } \\
\text { ATCC } \\
\text { BAA- } \\
1455\end{array}$ & $\begin{array}{c}7.62 \\
(15.24)\end{array}$ & $\begin{array}{c}15.24 \\
(30.48)\end{array}$ & $\begin{array}{c}7.62 \\
(30.48)\end{array}$ & $\begin{array}{c}3.81 \\
(30.48)\end{array}$ & 0.50 & 0.25 & 0.50 & $\begin{array}{c}1 / 3(0.50+ \\
0.25+0.50) \\
=0.42\end{array}$ & $\begin{array}{l}\text { syner } \\
\text { gistic }\end{array}$ \\
\hline $\begin{array}{l}\text { S. mutans } \\
\text { ATCC } \\
25175\end{array}$ & $\begin{array}{c}3.81 \\
(30.48)\end{array}$ & $\begin{array}{c}15.24 \\
(60.95)\end{array}$ & $\begin{array}{c}15.24 \\
(60.95)\end{array}$ & $\begin{array}{c}1.91 \\
(30.48)\end{array}$ & 0.50 & 0.13 & 0.13 & $\begin{array}{c}1 / 3(0.50+ \\
0.13+0.13) \\
=0.25\end{array}$ & $\begin{array}{l}\text { syner } \\
\text { gistic }\end{array}$ \\
\hline
\end{tabular}

585

The results are shown as average values of triplicate.

${ }^{\mathrm{a}} \mathrm{MIC}(\mathrm{MBC})$ : minimum inhibitory concentration (minimum bactericidal concentration)

bPEM: Plant extract mixture of Psidium sp., Mangifera sp. and Mentha sp. in ratio of 1:1:1 (w/v)

c $\Sigma F I C$ : the sum of fractional inhibitory concentration and was calculated according to the formula, $\Sigma \mathrm{FIC}=1 / 3\left(\mathrm{FIC}_{\mathrm{I}}+\mathrm{FIC}_{\mathrm{II}}+\mathrm{FIC}_{\mathrm{III}}\right)$

The $\Sigma$ FIC index was interpreted as interactions which are synergistic (if $<0.5$ ), additive (if in the range of $>0.5-1$ ) and indifferent (if in the range $>1-4$ ), or as antagonist (if $>4$ ). 
601 Table 2. Bacterial population in $\mathrm{CFU} / \mathrm{ml}$ for the negative control for $S$. sanguinis and $S$. mutans 602 singly and in the mixture.

603

\begin{tabular}{|l|c|}
\hline Bacteria & $\begin{array}{c}\text { Bacteria population adhered to the experimental } \\
\text { pellicle (negative control) }{ }^{\mathrm{a}}(\mathrm{mean} \pm \mathrm{SD})(\mathrm{CFU} / \mathrm{ml})\end{array}$ \\
\hline S. sanguinis ATCC BAA-1455 & $(2.30 \pm 0.37) \times 10^{6^{*}}$ \\
\hline S. mutans ATCC 25175 & $(2.48 \pm 0.16) \times 10^{7^{*}}$ \\
\hline $\begin{array}{l}\text { S. } \text { sanguinis ATCC BAA-1455+ } \\
\text { S. mutans ATCC 25175 }\end{array}$ & $(1.49 \pm 0.36) \times 10^{7}+(1.54 \pm 0.35) \times 10^{7}$ \\
\hline
\end{tabular}

604

605

606

607

608

609

610

611

612

613

614

615

616

617

618

619

620

621

622

623

624

625

626

627

628

629

630

631

632

633

634

The results are shown as average values of triplicate $(n=27)$ and are expressed in a mean $\mathrm{CFU} / \mathrm{ml} \pm$ standard deviation (SD).

${ }^{a}$ Negative control represents bacteria population adhered to the experimental pellicle-coated glass beads and was assumed as $100 \%$.

${ }^{*} p<0.05$ considered as significant.

.

1

3

4

16




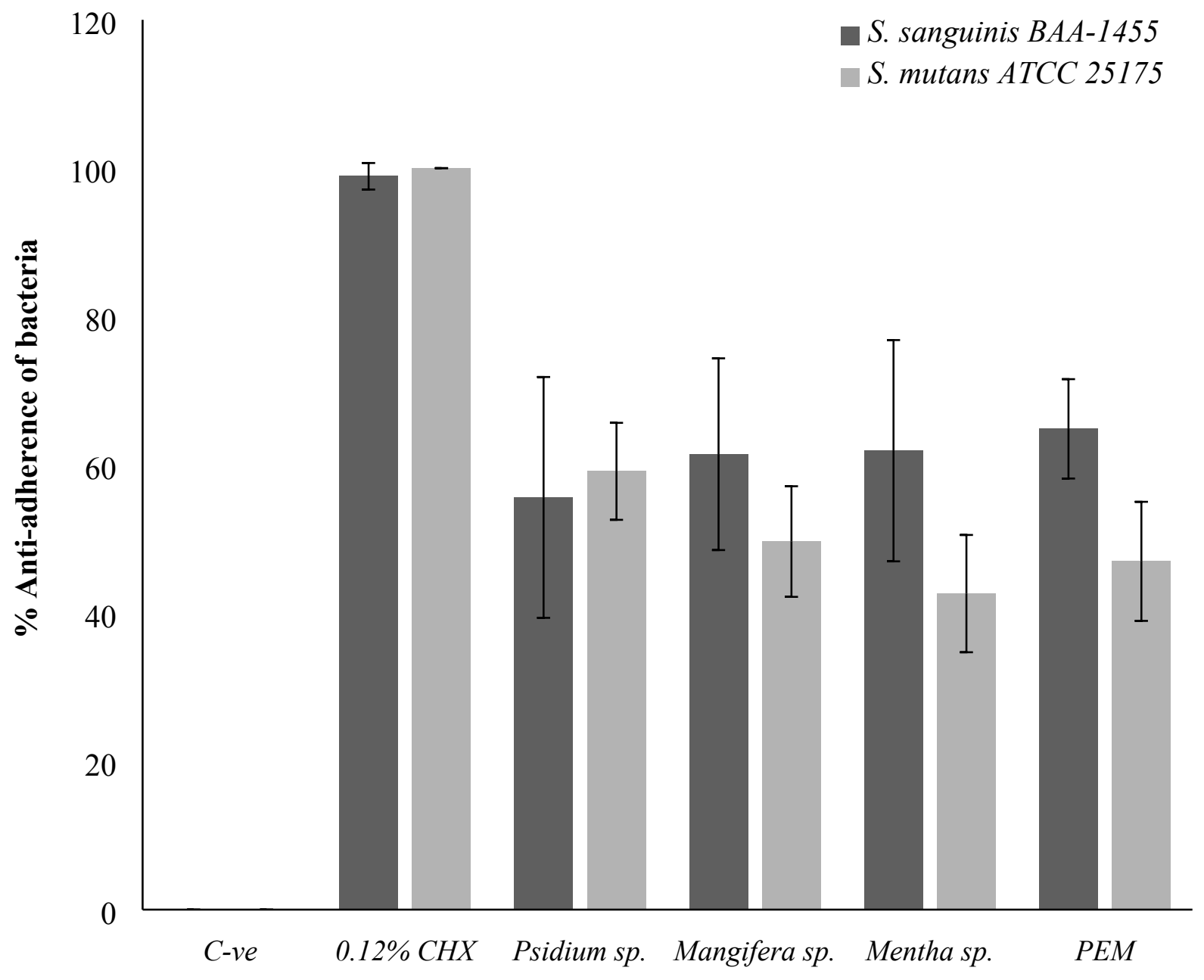

Fig. 1. The anti-adherence effect of PEM and its respective plant extracts in single-species

a- $p<0.05$ comparing between PEM, Psidium sp., Mangifera sp., Mentha sp., $0.12 \%$ CHX (positive control) and negative control (Kruskal-Wallis test).

b- $p<0.05$ comparing between PEM and Psidium sp., PEM and positive control and PEM and negative control (Mann-Whitney test).

c- $p<0.05$ comparing between $S$. sanguinis and $S$. mutans (treated with Mangifera $\mathrm{sp}$.), $S$. sanguinis and $S$. mutans (treated with Mentha sp.) and S. sanguinis and S. mutans (treated with PEM) (Mann-Whitney test). 
S. sanguinis $B A A-1455$

S. mutans ATCC 25175

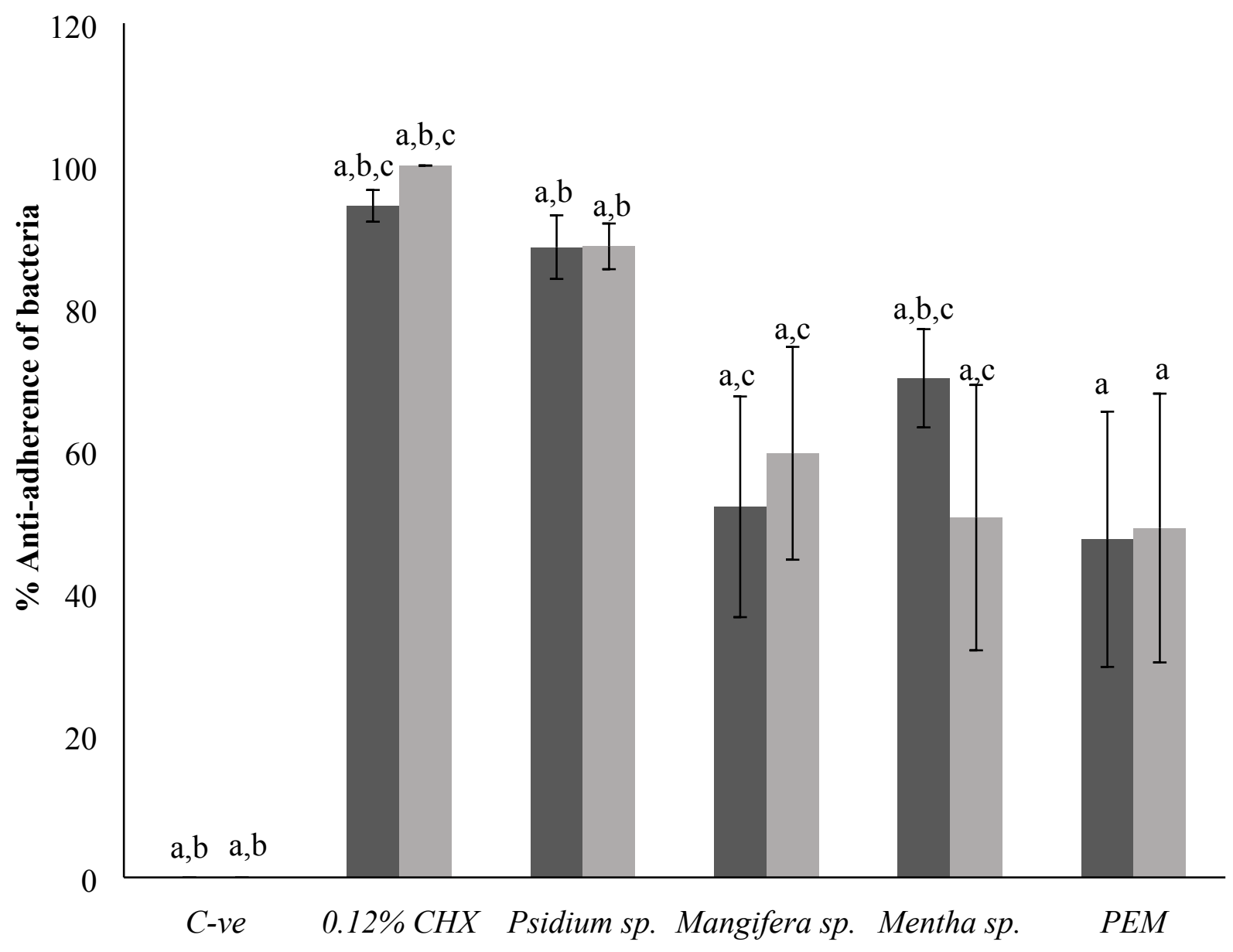

651 Fig. 2. The anti-adherence effect of PEM and its respective plant extract on dual-species 652 (S. sanguinis + S.mutans) biofilms. The percentage of anti-adhered bacterial cells present in the 653 biofilm was expressed as mean \pm standard deviation (SD) where a number of determinations $654(\mathrm{n})=27$.

a- $\quad p<0.05$ comparing between the respective PEM, Psidium sp., Mangifera sp., Mentha sp., $0.12 \% \mathrm{CHX}$ (positive control) and the negative control (Kruskal-Wallis test).

b- $p<0.05$ comparing between PEM and Psidium sp., PEM and Mentha sp. (for $S$. sanguinis), PEM and positive control and, PEM and negative control (Mann-Whitney test).

c- $p<0.05$ comparing between $S$. mutans and S. sanguinis (treated with Mangifera sp.), $S$. mutans and S. sanguinis (treated with Mentha sp.), S. mutans and S. sanguinis (treated with positive control) and, $S$. mutans and $S$. sanguinis (treated with negative control) (Mann-Whitney test). 



664

665 Fig. 3. The cell population of S. sanguinis viewed by Scanning Electron Microscopy (SEM) 666 where the pellicle was treated with PEM $\{\mathrm{C}\}$ and its respective plant extracts (Psidium sp $\{\mathrm{D}\}$; 667 Mangifera sp. $\{\mathrm{E}\}$ and Mentha sp. $\{\mathrm{F}\})$. The $0.12 \%$ chlorhexidine gluconate $\{\mathrm{B}\}$ and deionised 668 water $\{\mathrm{A}\}$ served as positive and negative controls respectively. Magnification: 10,000X. 

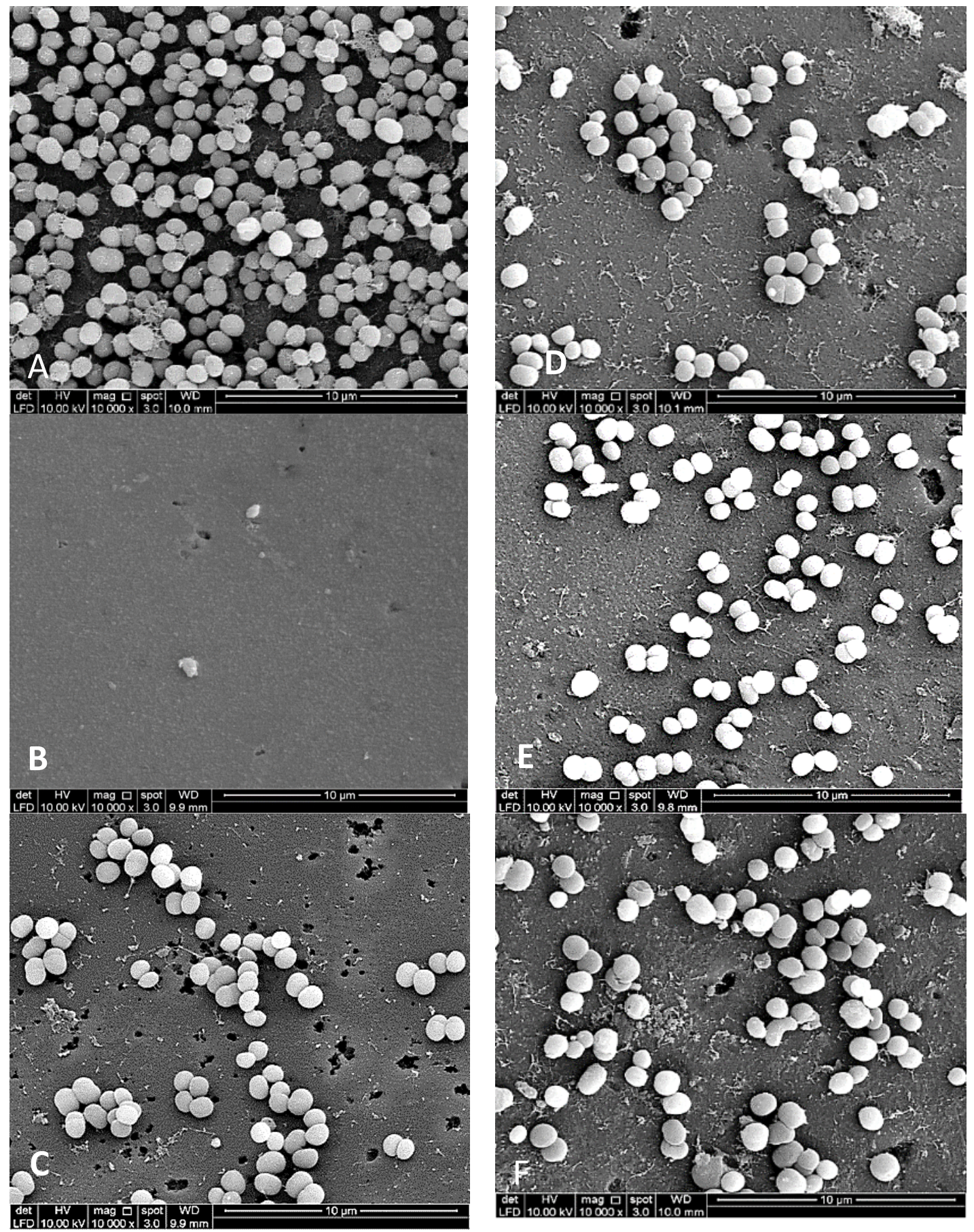

672 Fig. 4. The cell population of S. mutans viewed by Scanning Electron Microscopy (SEM) where 673 the pellicle was treated with PEM $\{\mathrm{C}\}$ and its respective plant extracts (Psidium sp $\{\mathrm{D}\}$; 674 Mangifera sp. $\{\mathrm{E}\}$ and Mentha sp. $\{\mathrm{F}\})$. The $0.12 \%$ chlorhexidine gluconate $\{\mathrm{B}\}$ and deionised 675 water $\{\mathrm{A}\}$ were served as positive and negative controls respectively. Magnification: 10,000X. 


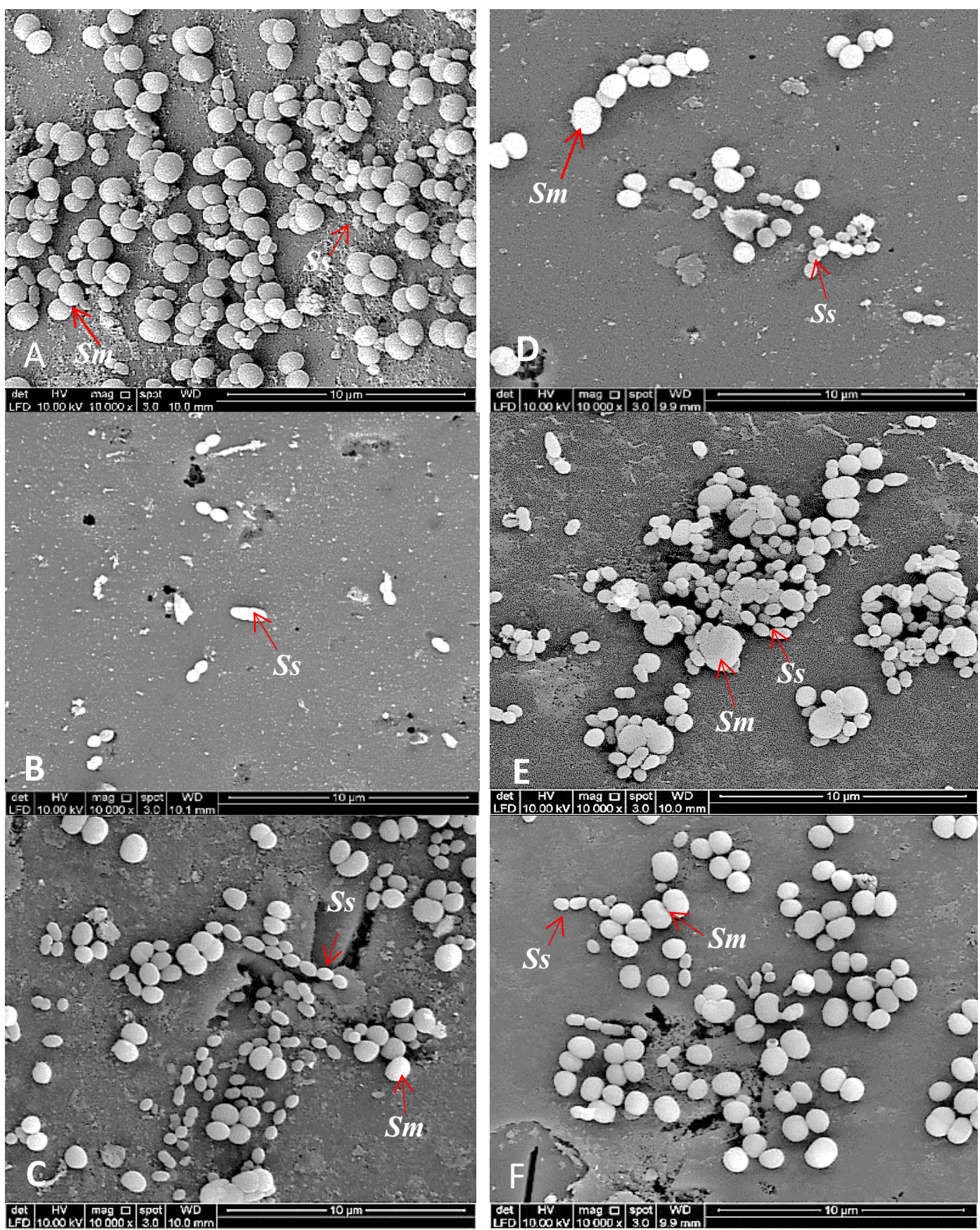

678 Fig. 5. The cell population of dual-species biofilms $(S$. sanguinis $(S s)+S$. mutans $(S m))$ viewed 679 by Scanning Electron Microscopy (SEM) where the pellicle was treated with PEM $\{C\}$ and its 680 respective plant extracts (Psidium sp. $\{\mathrm{D}\} ;$ Mangifera sp. $\{\mathrm{E}\}$ and Mentha sp. $\{\mathrm{F}\}$ ) on cell 681 adherence. The $0.12 \%$ chlorhexidine gluconate $\{\mathrm{B}\}$ and deionised water $\{\mathrm{A}\}$ were served as 682 positive and negative controls respectively. Magnification: 10,000X. 